Behavior and Social Issues, 26, 187-189 (2017). (C) Molly Benson. Readers of this article may copy it without the copyright owner's permission, if the author and publisher are acknowledged in the copy and the copy is used for educational, not-for-profit purposes. doi: 10.5210/bsi.v.26i0.7397

\title{
Advocating FOR ACTIVISM
}

\author{
Molly Benson ${ }^{1}$ \\ Behaviorists for Social Responsibility
}

The other night while eating dinner, my boyfriend's youngest child asked what "boycott" meant. I gave the best example of activism that I could explain: Martin Luther King Jr., Rosa Parks, and the Montgomery Bus Boycott, which lasted 381 days. The success of the boycott depended on tens of thousands of African American individuals, who were heavily reliant upon public transportation, refusing to ride for over a year. The boycott was effective in simple behavioral terms of my own definition of activism: a high rate of behavior sustained over a period of time amongst a verbal or cultural group for demonstrable gain.

The Montgomery Bus Boycott is only one of many examples of activism that demonstrate its necessity in order to ensure the promise of representative democracy. An ongoing threat to the democratic process is economic control by outside agencies, presenting elected leaders with choices to make between public good and economic gain. These competing contingencies are issuing a call for the involvement of behavior analysts, who are well-suited to determine functional relations and interventions that will influence elected officials to answer to the will of the people. So long as our elected officials rely to a meaningful degree on the democratic process to maintain their positions, constituents have the ability to yield great power through coordinated efforts and activism, and behavior analysts can create opportunities requiring manageable response effort, where constituents are motivated to act, and reinforcement is provided. Reinforcement, the defining principle of applied behavior analysis, is the means by which activists can serve as a check on government.

B.F. Skinner was concerned about government. He saw it as "the use of the power to punish" (1953, p. 335), and postulated that escape, revolt, and passive resistance are results of excessive control of the governed (Skinner, 1948, 1953, 1971). These behaviors closely resemble the most commonly used activist strategies: protest, disruptive noncooperation, resource interruption, and retaliation. Thus one could say that much of activism, as a byproduct of punishment, is an example of countercontrol. Alternative strategies include persuasion, which relies primarily on establishing operations, shifts in relational responding, and reinforcement; and constructive noncooperation, which prioritizing building an alternative culture or society, a potentially less aversive and yet still powerful approach to disrupting injustice (Mattaini, 2013). The challenge for us then is to lend our knowledge of contingency management and constructing functional interlocking contin-gencies to activist efforts to impact change for the greater good and to broaden our activist base, without the adverse side effects of punishment. As behavior analysts, we are in unique possession of promising

\footnotetext{
${ }^{1}$ Molly Benson is a Board Certified Behavior Analyst. She can be reached at bensonmolly@ hotmail.com
} 


\section{BENSON}

technologies to contribute to positive change through the use of reinforcement and constructional processes as means of social influence.

There are abundant opportunities for sustained collaborative efforts, outside of government and within, to produce measured change. Behavior analysts make excellent "Planners" Skinner, 1948), and are no strangers to manipulating environments to maximize performance and produce desired outcomes. We are therefore well suited for positions in government, volunteer-based or elected. Our ability to operationally define and quantify dimensions of human behavior puts us in a unique position to participate in government, measuring human losses and gains, when stacked against economic growth. Clear definitions and measurement can help provide accountability for elected or appointed officials engaged in decision making. For these reasons, and challenges to the democratic process that prevent us from adopting policy commensurate to our societal problems, I am using this piece of writing to encourage behavior analysts to become involved in activist efforts. Acting locally, as I discovered, is a great place to start.

My first experience with activism was a land development/rezoning issue in my hometown of Beverly, Massachusetts. In spite of widespread opposition from neighbors and a public hearing lasting until midnight, our Planning Board made a rezoning decision in favor of a developer that would ultimately result in a commercial plaza being built in the middle of our street. My neighbors mobilized, successfully petitioning for a Special Election to overturn the rezoning decision. We began campaigning, and I was selected to serve on a Task Force with the city.

This first experience with activism showed me where grassroots efforts are best focused: collaboration building, determining factually relevant information, educating the public, establishing behavioral momentum, rewarding approximations, and using communication that motivates and reinforces. It also brought to my attention the recurring theme of social media as an automatic weapon which provides us a platform and the ability to help and disseminate widely; or, conversely, to perpetuate misinformation, distance ourselves from each other, impair our ability to come to consensus, contribute to feelings of anxiety, even amongst friends.

Around this same time, I left my position as a BCBA in a school district and joined onto the Hawaii Association for Behavior Analysis' efforts to ensure the passage of autism insurance legislation and BCBA licensure. My aim was to observe and take part in grassroots efforts lead by Behavior analysts. My arrival coincided with a huge legislative push after years of concerted effort. So while I was present for Hawaii becoming the 42nd state to adopt Autism Insurance Legislation, I knew it was due to the sustained efforts of many, over an extended period of time. The lessons I learned from my HABA friends through their grassroots efforts have lingered past my departure. In Hawaii, I gained a sense of what is possible when we coordinate and organize our ABA state chapters effectively, applying our Behavior Analytic lens to tackle legislative endeavors.

To begin with, the Hawaii Association for Behavior Analysis is an organized and efficient Association for Behavior Analysis: International (ABAI) chapter. Having taken part in grassroots efforts with my neighbors, I recognized the challenges to organizing and communicating, the need for rapid response, and competing time demands. HABA, well-structured and organized, had this down. First of all, accessibility wasn't a barrier for participation even though members live among islands because they utilized technology to communicate effectively. Secondly, HABA not only had a governing board, but a Legislative Committee (which I joined upon my arrival) that they developed in response to Legislative demands. Chair positions were elected and committee membership was volunteer based. All forms of participation were valued, from cookie making, to calling reporters and providing testimony. When Legislative Chairs weren't present, other members assumed responsibility. HABA's Legislative Committee built a coalition among 


\section{ADVOCATING FOR ACTIVISM}

advocacy groups, and identified pillars of support for opposition groups. This small group of Behavior Analysts were using a behavioral systems approach to strategize, effectively educating, collaborating, advocating, and participating in the democratic process. Messaging was positive and concise about what people could do to help, and response effort was reduced for people to contribute. All gains, no matter how incremental, were shared and celebrated amongst the group. Everyone was getting ABA'd.

Through my experience in Hawaii with HABA's Legislative Committee, I saw how behavior analysts can play a role in shaping policy when we organize ourselves within our own profession and chapters, which is exactly what we have done through autism insurance legislation and licensure. Now if we keep legislative committees intact past the point of autism insurance reform, ABA chapters can choose pertinent issues within their state to address, for example, homelessness and plastic bag consumption. Collectively, state chapters can choose to work on a Federal issue like education, health care, or renewable energy. Legislative committees, in addition to their policy shaping efforts, provide competency building and practicum opportunities in non-traditional areas for Behavior Analysts, and promote a culture of activism. Our policy contributions to autism insurance legislation and licensure alone are evidence of the impact we can have on legislative outcomes. It is this belief that guides my work today.

Since leaving full-time employment and beginning grassroots activism, I have become an even more active member of the behavior analytic community. I attend state conferences to build competency and collaborate with other behavior analysts working in the field of policy, government, and sustainability. I also volunteer and perform grant work through the North Carolina Clean Energy Technology Center. Somehow along the way, my "career" started to matter less than what I was able to accomplish through my sustained participation within these collaborations whose efforts, when they align with mine, I can more effectively help than by addressing behavior change through isolated attempts. When people ask me what I do, I can tell them, "I am an activist."

But being an activist can be challenging. It is a tremendous undertaking without clear or immediate reinforcement and can require real sacrifice (I could write a separate article about dwindling savings and access to healthcare). However as a behavior analyst I understand the challenges to behavior that comes from delays of reinforcement, and can plan accordingly to address these hurdles. Activist efforts have been opportunities for relationship and competency building outside clinics and classrooms, and have given me opportunities to address societal issues while ultimately producing measurable change. Saving the world with behavior analysis is my dream, and I want those who share it with me to have the conviction that we can start by addressing societal problems at a systems level, through our activist efforts.

The children at my dinner table may never witness a movement the size and scale of the Civil Rights Movement, but they live in an era of unparalleled threat to democratic principles and process. If activism starts at home, then the decision they made to only eat fair trade chocolate is certainly a start that I can support in my shopping....as long as they don't boycott the vegetables.

\section{References}

Mattaini, M.A. (2013) Strategic Nonviolent Power: The Science of Satyagraha. Canada: AU Press.

Skinner, B.F. (1971). Beyond Freedom \& Dignity. Indianapolis: Hackett

Skinner, B.F. (1953). Science and Human Behavior. New York: MacMillan

Skinner, B.F. (1948). Walden Two. New York: MacMillan. 